\title{
Laboratory Evaluation of Rejuvenating Agent on Reclaimed SBS Modified Asphalt Pavement
}

\author{
Jie Wang * (1), Wei Zeng *, Yongchun Qin, Songchang Huang and Jian Xu \\ Research Institute of Highway Ministry of Transport, Beijing 100088, China; yc.qin@rioh.cn (Y.Q.); \\ sc.huang@rioh.cn (S.H.); j.xu@rioh.cn (J.X.) \\ * Correspondence: j.wang@rioh.cn (J.W.); w.zeng@rioh.cn (W.Z.); Tel.: +86-010-6207-9525 (J.W. \& W.Z.) \\ Academic Editors: Zhanping You, Qingli (Barbara) Dai and Feipeng Xiao \\ Received: 13 June 2017; Accepted: 19 July 2017; Published: 21 July 2017
}

\begin{abstract}
To evaluate the effect of rejuvenating agent on reclaimed SBS (styrene-butadiene-styrene) modified asphalt pavement (RSMAP) material, different tests of asphalt and mixtures were conducted. Firstly, the improvement effect of rejuvenating agents on the aged modified asphalt was tested at macroscopic and microscope level. Then the properties of hot mix asphalt (HMA) with different RSMAP contents $(0 \%, 30 \%, 50 \%$ and $70 \%)$ were evaluated by conducting freeze-thaw split, semi-circular bending (SCB) and dynamic modulus (DM). The results indicate that rejuvenating agent can recycle the properties of aged modified asphalt effectively. The initial phase structure of the aged modified asphalt is not changed by adding rejuvenating agents. Moreover, the SBS particles area ratio of modified asphalt blends is significantly correlated with tenacity as the proportion of rejuvenating agent increases. For mixtures, RSMAP is harmful to moisture susceptibility and low-temperature cracking resistance of recycled mixture, especially with high RSMAP content. Moreover, the two properties can be improved by adding rejuvenating agents, but the recycled mixtures with high RSMAP content are not easy to recover to HMA mixture level. In general, the rejuvenating agent has an effect on the stiffness of the recycled mixture, but this is effect not obvious. When loading frequency reaches a higher value, the DM of recycled mixtures and HMA mixture tend to be consistent including high RSMAP content.
\end{abstract}

Keywords: road engineering; reclaimed SBS modified asphalt pavement; rejuvenating agent; phase structure; fracture energy; fracture toughness; stiffness

\section{Introduction}

Polymer modified asphalt has been widely applied in the construction and maintenance of asphalt pavement in China since the 1990s in order to adapt to the heavy load of modern traffic, and effectively resist the adverse effect of environmental conditions [1,2]. (styrene-butadiene-styrene) SBS modified asphalt is most widely used as it has the advantages of adequate stability under high temperature and low temperature, and satisfactory elastic resilience [3-5]. Especially in the 21st century, SBS modified asphalt has been extensively used in China for the surface layer construction of asphalt pavement, and it is also used for the construction of many asphalt middle layers [6,7].

A large number of SBS modified asphalt pavements have entered into or are approaching the overhaul period considering their designed life goal of 15 years, given the high traffic volume, and overloaded vehicles in China. The maintenance of modified asphalt pavements is facing the problem of disposal of reclaimed SBS modified asphalt pavement (RSMAP). If RSMAP cannot be used rationally, it will lead to serious environmental pollution and economic losses. Therefore, the recycling of RSMAP has become a focus of highway maintenance in China [8,9]. Currently, there are many in-depth studies on the asphalt recycling [10-12] with many successful applications in China. However, the studies on 
SBS modified asphalt recycling need to be further expanded. Some questions that need to be answered include whether the aged modified asphalt can be effectively recycled; the role of rejuvenating agent in aged modified asphalt; the effect of different types and proportion of rejuvenating agents on the properties of aged modified asphalt and HMA with different RSMAP contents, especially for high content [13-15]. In addition, the studies of the low-temperature cracking resistance, which is one of the most properties of recycled mixtures, are relatively few in number [16]. These questions make the recycling of aged modified asphalt uncertain.

SBS modified asphalt is a multiphase blend composed of polymer SBS and asphalt $[17,18]$. The two kinds of materials exist with differences in molecular weight and chemical structure as a thermodynamically incompatible system. Because of the interface interaction between different components, it is difficult for the blends to reach a homogeneous level and just achieve physical structure compatibility. The differences of compatibility has lead to a great differences in the properties of modified asphalt [19]. Therefore, the phase structure of SBS modified asphalt can generally be divided into three types: (1) single-phase continuous structure with SBS polymer as dispersed phase and asphalt phase as continuous phase. This type is more common in highway construction; (2) single-phase continuous structure with SBS polymer as continuous phase and asphalt phase as dispersed phase; (3) two-phase continuous structure with SBS polymer and asphalt phase both as continuous phase. The different phase structure has a significant impact on the properties of modified asphalt $[20,21]$. Ignoring the phase structure to study modified asphalt recycling is not appropriate. This study takes into consideration the phase characteristics of modified asphalt. It focuses on the role of rejuvenating agent in aged modified asphalt, and the effect of rejuvenating agent on properties of recycled mixtures, including high RSMAP content. This study is intended to further clarify the recycling mechanism of rejuvenating agent on RSMAP.

\section{Materials and Methods}

\subsection{Materials}

The RSMAP material used in this paper was obtained from Beijing, and the aged modified asphalt extraction from the mixture was performed by Abson method [22]. The aged asphalt content of RSMAP is $3.6 \%$, and the main properties of the aged modified asphalt and virgin SBS modified asphalt used in the study are shown in Table 1.

Table 1. Main properties of modified asphalt.

\begin{tabular}{|c|c|c|}
\hline Properties & Aged Modified Asphalt & Virgin Modified Asphalt \\
\hline Penetration $\left(25^{\circ} \mathrm{C}\right) / 0.1 \mathrm{~mm}$ & 36.3 & 48.1 \\
\hline Softening point $/{ }^{\circ} \mathrm{C}$ & 68.8 & 69.3 \\
\hline Ductility $\left(5^{\circ} \mathrm{C}\right) / \mathrm{cm}$ & 0.1 & 30.7 \\
\hline Viscosity $\left(135^{\circ} \mathrm{C}\right) / \mathrm{Pa} \cdot \mathrm{s}$ & 2.24 & 1.05 \\
\hline Maximum tension/N & 599.9 & 332.7 \\
\hline Toughness/N·m & 17.74 & 13.52 \\
\hline Tenacity/N.m & 6.65 & 9.87 \\
\hline
\end{tabular}

Three rejuvenating agents with different viscosity were selected in this study in order to evaluate the recycling effect on the aged modified asphalt, and represented by H, S, G respectively. The main properties of the rejuvenating agents were tested according to ASTM D4552 and the results are shown in Table 2. 
Table 2. Main properties of rejuvenating agent.

\begin{tabular}{|c|c|c|c|c|c|c|c|}
\hline \multirow{2}{*}{ Type } & \multirow{2}{*}{$\begin{array}{c}\text { Viscosity } \\
\left(60^{\circ} \mathrm{C}\right) / 10^{-3} \mathrm{~Pa} \cdot \mathrm{s}\end{array}$} & \multirow{2}{*}{$\begin{array}{c}\text { Flash } \\
\text { Point } /{ }^{\circ} \mathrm{C}\end{array}$} & \multirow{2}{*}{$\begin{array}{l}\text { Saturates } \\
\text { Content } / \%\end{array}$} & \multirow{2}{*}{$\begin{array}{l}\text { Aromatic } \\
\text { Content } / \%\end{array}$} & \multirow{2}{*}{ Density $/ \mathrm{g} \cdot \mathrm{cm}^{-3}$} & \multicolumn{2}{|c|}{ Tests on Residue from TFOT } \\
\hline & & & & & & Viscosity Ratio* & Weight Change/\% \\
\hline $\mathrm{H}$ & 123 & 256 & 17.07 & 62.07 & 1.002 & 2.3 & -3.34 \\
\hline G & 2607 & 278 & 25.98 & 49.81 & 1.028 & 1.4 & -2.73 \\
\hline
\end{tabular}

${ }^{*}$ Viscosity ratio $=$ Viscosity $\left(60^{\circ} \mathrm{C}\right)$ of residue from TFOT/Virgin viscosity $\left(60^{\circ} \mathrm{C}\right)$.

In the process of aggregate gradation design of recycled mixtures with different RSMAP contents, the gradation should be as similar as possible. AC-13 is selected as the type of recycled mixtures. The virgin coarse aggregate is basalt, the crushing value is $14.3 \%$, and the Los Angeles abrasion value is $13.5 \%$ [23]. The virgin fine aggregate is limestone. Table 3 shows the aggregate gradation and asphalt content of recycled mixtures with different RSMAP contents $(0 \%, 30 \%, 50 \%$ and $70 \%)$. The type of rejuvenating agent for recycled mixtures used in this study is $\mathrm{S}$.

Table 3. Aggregate gradation and asphalt content of recycled mixtures with different reclaimed SBS (styrene-butadiene-styrene) modified asphalt pavement (RSMAP) contents.

\begin{tabular}{ccccc}
\hline \multirow{2}{*}{ Sieve Size/mm } & \multicolumn{4}{c}{ Type of Recycled Mixtures } \\
\cline { 2 - 5 } & $\mathbf{0 \%}$ & $\mathbf{3 0 \%}$ & $\mathbf{5 0 \%}$ & $\mathbf{7 0} \%$ \\
\hline 16 & 100.0 & 100.0 & 100.0 & 100.0 \\
13.2 & 97.3 & 97.2 & 97.0 & 96.9 \\
9.5 & 75.1 & 75.0 & 73.4 & 72.6 \\
4.75 & 41.9 & 41.9 & 40.4 & 40.7 \\
2.36 & 28.1 & 29.1 & 28.2 & 28.4 \\
1.18 & 18.2 & 18.7 & 18.4 & 18.6 \\
0.6 & 13.6 & 13.8 & 13.7 & 14.0 \\
0.3 & 10.2 & 10.3 & 10.3 & 10.6 \\
0.15 & 8.0 & 7.9 & 8.0 & 8.4 \\
0.075 & 6.3 & 6.2 & 6.4 & 6.7 \\
Virgin asphalt content/\% & 0.0 & 3.7 & 3.1 & 2.4 \\
Total asphalt content/\% & 4.8 & 4.8 & 4.9 & 5.0 \\
\hline
\end{tabular}

\subsection{Methods}

The aged modified asphalt was blended with three types of rejuvenating agents with the proportion of $3 \%, 6 \%$ and $9 \%$ by mass of aged modified asphalt, respectively. The tests include the macroscopic properties of $25^{\circ} \mathrm{C}$ penetration, softening point, $5{ }^{\circ} \mathrm{C}$ ductility, $135{ }^{\circ} \mathrm{C}$ Brookfield viscosity, toughness and tenacity [22]. The phase characteristics of the modified asphalt were evaluated using fluorescence microscope.

The properties of recycled mixtures in this study mainly focus on moisture susceptibility, low-temperature cracking resistance and stiffness. Conducted tests included freeze-thaw split [22], semi-circular bending (SCB) and dynamic modulus (DM).

\subsection{Semi-Circular Bending Test}

The SCB test is used as a method for evaluating asphalt mixture cracking resistance [24]. The test configuration and sample size are illustrated in Figure 1. Test samples were fabricated using SGC at 7 $\pm 0.5 \%$ air void. SGC-compacted samples were $10 \mathrm{~cm}$ in height and $15 \mathrm{~cm}$ in diameter; each sample was trimmed to half-disc-shaped samples $15 \mathrm{~cm}$ in diameter and $5 \mathrm{~cm}$ thick. The notch is cut in the middle point of the lower surface of the sample to ensure that the crack will initiate at the desired point. In this study, the notch depth was $1.5 \mathrm{~cm}$. The test was conducted at $-20{ }^{\circ} \mathrm{C}$ and $-10{ }^{\circ} \mathrm{C}$ at constant loading rate of $1 \mathrm{~mm} / \mathrm{min}$. 
In order to evaluate the crack resistance of recycled mixtures, fracture energy $\left(G_{f}\right)$ is used, which can be obtained by dividing fracture work with ligament area [25], as provided in Equation (1). The total fracture work can be calculated by the area under the $P$ - $u$ curve. Figure $1 \mathrm{~d}$ shows a typical SCB load versus displacement curve.

$$
G_{f}=\frac{W_{f}}{A_{l i g}}
$$

where $G_{f}=$ fracture energy $\left(\mathrm{J} / \mathrm{m}^{2}\right) ; A_{\text {lig }}=$ ligament area $\left(\mathrm{m}^{2}\right)=(r-a) \times t ; r=$ specimen radius $(\mathrm{m}) ; a=$ notch depth $(\mathrm{m}) ; t=$ specimen thickness $(\mathrm{m})$; and $W_{f}$ can be calculated as follows in Equation(2).

$$
W_{f}=\int P d u
$$

where $P=$ applied load $(\mathrm{kN})$; and $u=$ load line displacement $(\mathrm{mm})$.

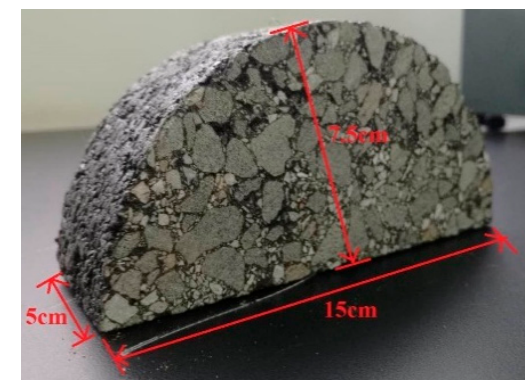

(a)

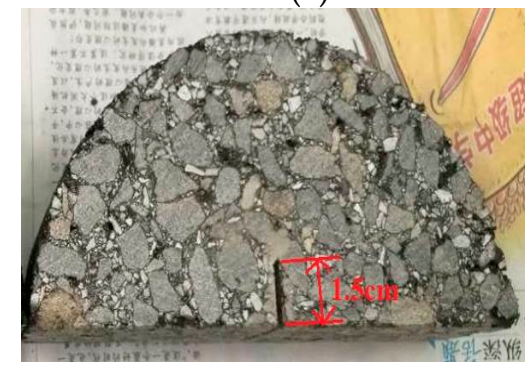

(c)

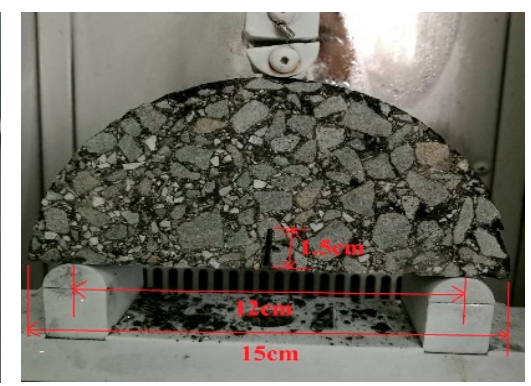

(b)

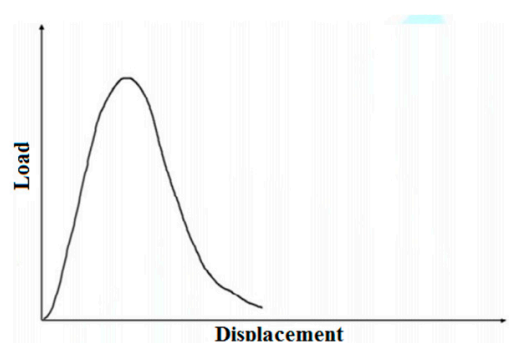

(d)

Figure 1. (a) Sample dimensions; (b) semi-circular bending (SCB) test configuration; (c) samples with a notch depth; (d) typical SCB load versus displacement $(P-u)$ curve.

Fracture toughness $\left(K_{c}\right)$ is considered as the stress intensity factor at the critical load $\left(P_{c}\right)$, and provides a single parameter characterization that includes the effect of specimen configuration, boundary conditions, and load. In addition, $K_{c}$ is qualified as an intrinsic material property, describing the ability to resist cracking [26]. In this paper, $K_{c}$ is calculated using the following equation.

$$
K_{c}=Y_{I} \sigma_{c} \sqrt{\pi a}
$$

where $\sigma_{c}=P_{c} / 2 r t ; Y_{I}=4.782+1.219(a / r)+0.063 \exp [7.045(a / r)] ; P_{c}=$ peak load; $Y_{I}=$ normalized stress intensity factor.

\subsection{Dynamic Modulus Test}

Dynamic modulus $\left(E^{*}\right)$ is a fundamental property of asphalt mixture that defines the viscoelastic stiffness as a function of loading rate and temperature. In this study, test samples were fabricated using SGC at $7 \pm 0.5 \%$ air void. SGC-compacted samples were $17 \mathrm{~cm}$ in height and $15 \mathrm{~cm}$ in diameter, and the samples were cored and trimmed to $15 \mathrm{~cm}$ in height and $10 \mathrm{~cm}$ in diameter. DM tests were conducted at three temperatures $\left(4^{\circ} \mathrm{C}, 20^{\circ} \mathrm{C}, 40^{\circ} \mathrm{C}\right)$ and six frequencies $(25 \mathrm{~Hz}, 10 \mathrm{~Hz}, 5 \mathrm{~Hz}, 1 \mathrm{~Hz}$, 
$0.5 \mathrm{~Hz}, 0.1 \mathrm{~Hz}$ ) using asphalt mixture performance test (AMPT, IPC Global, Victoria, Australia) and following AASHTO T342-11, as shown in Figure 2.

The stress level and the number of loading cycles in the test are shown in Tables 4 and 5 respectively.

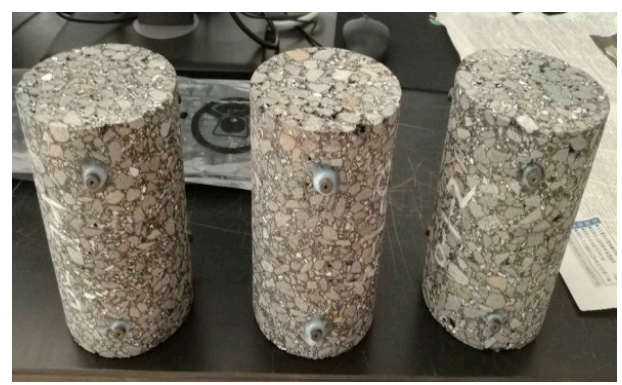

(a)

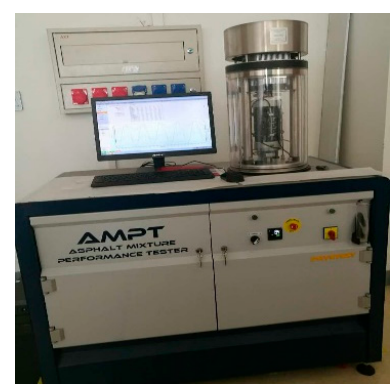

(b)

Figure 2. (a) Three parallel sample; (b) asphalt mixture performance test (AMPT) equipment.

Table 4. The stress level (kPa) of dynamic modulus (DM) test.

\begin{tabular}{cccc}
\hline \multirow{2}{*}{ Loading Frequency/Hz } & \multicolumn{3}{c}{ Test Temperature $/{ }^{\circ} \mathbf{C}$} \\
\cline { 2 - 4 } & $\mathbf{4}$ & $\mathbf{2 0}$ & $\mathbf{4 0}$ \\
\hline 25 & 1400 & 700 & 250 \\
10 & 1260 & 630 & 228 \\
5 & 1120 & 560 & 206 \\
1 & 980 & 490 & 184 \\
0.5 & 840 & 420 & 162 \\
0.1 & 700 & 350 & 140 \\
\hline
\end{tabular}

Table 5. The number of loading cycles of DM test.

\begin{tabular}{cc}
\hline Loading Frequency/Hz & Number of Loading Cycles \\
\hline 25 & 200 \\
10 & 200 \\
5 & 100 \\
1 & 20 \\
0.5 & 15 \\
0.1 & 15 \\
\hline
\end{tabular}

Using the dynamic modulus test results measured at three different temperatures and six different loading frequencies, the master curves of recycled mixtures based on the time-temperature superposition principle were constructed for a reference temperature of $20^{\circ} \mathrm{C}$ [27]. The sigmoidal function is used to fit and develop the master curve, as provided in Equation (4).

$$
\log \left|E^{*}\right|=\delta+\frac{a}{1+\exp \left(\beta+\gamma\left(\log f_{r}\right)\right)}
$$

where $\left|E^{*}\right|=$ dynamic modulus $(\mathrm{MPa}) ; f_{r}=$ reduced frequency at reference temperature; $\delta=$ minimum value of $\left|E^{*}\right| ; \delta+\alpha=$ maximum value of $\left|E^{*}\right| ; \beta, \gamma=$ fitting parameters.

Equation (5) shows the temperature shift factor.

$$
\log \left(f_{r}\right)=\log (a(T))+\log (f)
$$

where $a(T)=$ temperature shift factor; $f=$ frequency at a particular temperature. 
The temperature shift factor may be written in the form of Equation (6) by using the Arrhenius time-temperature superposition model [28].

$$
\log (a(T))=c\left(\frac{1}{T_{k}}-\frac{1}{T_{r e f}}\right)
$$

where $T_{k}=$ the test temperature in Kelvin temperature; $T_{r e f}=$ the reference temperature in Kelvin temperature; $c=$ nonlinear fitting curve coefficient.

A nonlinear optimization program in 1stOpt software was used to determine the master curve coefficients.

\section{Results and Analyses}

\subsection{Macroscopic Properties of Rejuvenating Agents on Aged Modified Asphalt}

It is well known that the stiffness of modified asphalt will increase after aging, resulting in attenuation of the low-temperature property and improvement for the high-temperature property. Consequently, modified asphalt recycling should focus on the recovery of low-temperature properties. Table 6 and Figures 3 and 4 show the results of different types of rejuvenating agents on aged modified asphalt.

Table 6. The effect of rejuvenating agent on aged modified asphalt.

\begin{tabular}{ccccccccccc}
\hline \multirow{2}{*}{ Indexes } & \multirow{2}{*}{ Aged Modified Asphalt } & \multicolumn{4}{c}{$\mathbf{H}$} & \multicolumn{4}{c}{$\mathbf{S}$} & \multicolumn{3}{c}{$\mathbf{G}$} \\
\cline { 3 - 10 } & & $\mathbf{3 \%}$ & $\mathbf{6 \%}$ & $\mathbf{9 \%}$ & $\mathbf{3} \%$ & $\mathbf{6 \%}$ & $\mathbf{9 \%}$ & $\mathbf{3 \%}$ & $\mathbf{6 \%}$ & $\mathbf{9 \%}$ \\
\hline Penetration/0.1 mm & 36.3 & 50 & 85 & 108 & 46 & 50 & 62 & 39 & 49 & 57 \\
Softening point $/{ }^{\circ} \mathrm{C}$ & 68.8 & 64.9 & 59.4 & 59.2 & 64.5 & 64.3 & 62 & 67.2 & 64.2 & 62.3 \\
Ductility/cm & 0.1 & 19.3 & 25.9 & 39.3 & 17.8 & 21.2 & 29.6 & 13.7 & 20.7 & 35.7 \\
Viscosity/Pa.s & 2.24 & 1.07 & 0.83 & 0.64 & 1.07 & 1.01 & 0.88 & 1.26 & 1.01 & 0.81 \\
\hline
\end{tabular}

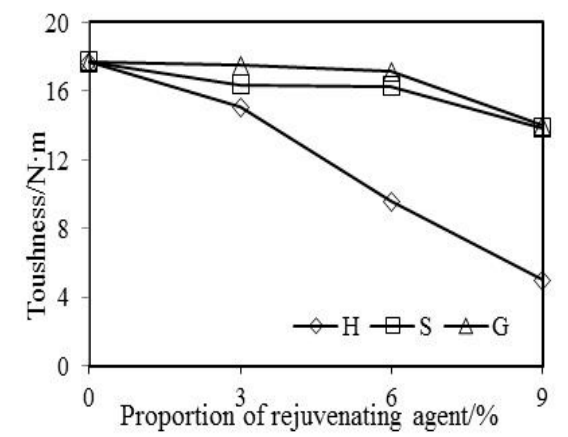

(a)

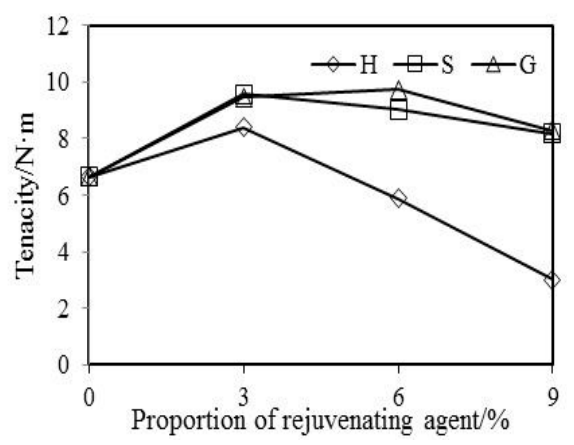

(b)

Figure 3. Relationship between (a) toughness, (b) tenacity and proportion of Rejuvenating Agent.

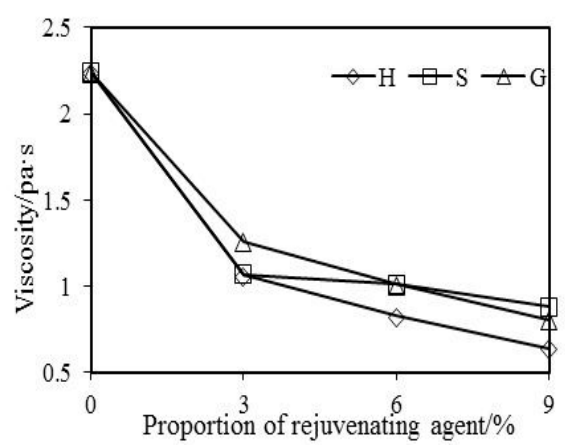

Figure 4. Relationship between penetration and viscosity. 
Table 6 shows that: with the increasing of rejuvenating agent proportion, softening point and viscosity decrease, while penetration and ductility increase. When the proportion of $\mathrm{H}, \mathrm{S}, \mathrm{G}$ is $9 \%$, the ductility of modified asphalt blends increases from brittle fracture to $39.3 \mathrm{~cm}, 29.6 \mathrm{~cm}$ and $35.7 \mathrm{~cm}$ respectively, which indicates that the rejuvenating agent can recover the low-temperature property of modified asphalt. Satisfactory results can be achieved which indirectly prove the sufficient feasibility of modified asphalt recycling.

From Figure 3, the toughness decreases continuously as the rejuvenating agent proportion increases, and the trend of tenacity is different. When the proportion of rejuvenating agent is small, the tenacity increases at first, and then decreases when the proportion increases continuously, probably because the rejuvenating agent is beneficial to the improvement of swelling effect between polymer SBS and asphalt. Moreover, it can partially improve the mechanical properties of modified asphalt. The tenacity increase can also indirectly prove the feasibility of modified asphalt recycling. When the proportion of rejuvenating agent increases further, the tenacity of modified asphalt blends begins to decrease due to reduced viscosity.

Figure 4 indicates that the penetration of modified asphalt blends increases with the decreasing of viscosity, but the trend is not linear. When the viscosity of modified asphalt blends is more than $1.1 \mathrm{~Pa} \cdot \mathrm{s}$, the change of penetration along with the viscosity is not obvious. However, the penetration increases noticeably with the decreasing of viscosity, roughly showing linear relationship when the viscosity of modified asphalt blends is less than $1.1 \mathrm{~Pa} \cdot \mathrm{s}$. This phenomenon indicates that the viscosity must be less than a certain value for the change of penetration to be obvious, and this result is similar to the conclusion of reference [29].

In conclusion, the rejuvenating agent can partially or completely recycle the properties of aged modified asphalt. Increasing the proportion of rejuvenating agent can better improve the low-temperature ductility. However, the correlation of penetration, ductility and softening point indicates that increasing the proportion of rejuvenating agent to improve ductility will lead to a sharp increase of penetration and a decrease of softening point. For example, when the proportion of $\mathrm{H}$ is $6 \%$, the penetration of modified asphalt blend is $85(0.1 \mathrm{~mm})$. However, the ductility is still relatively small. The results indicate that the recycling of penetration and ductility is not synchronous and it is not appropriate to use the penetration and ductility to carry on the design of modified asphalt recycling at the same time.

\subsection{Anti-Aging Property of Modified Asphalt Blends}

To examine the anti-aging property of modified asphalt blends, the thin film oven test (TFOT) was conducted. According to the recycling effect and economy of the above-mentioned three rejuvenating agents $\mathrm{H}, \mathrm{S}, \mathrm{G}$, the proportion of rejuvenating agent for TFOT were set to $3 \%, 6 \%, 6 \%$ respectively. The test results are shown in Table 7.

Table 7. Anti-aging property of modified asphalt blends.

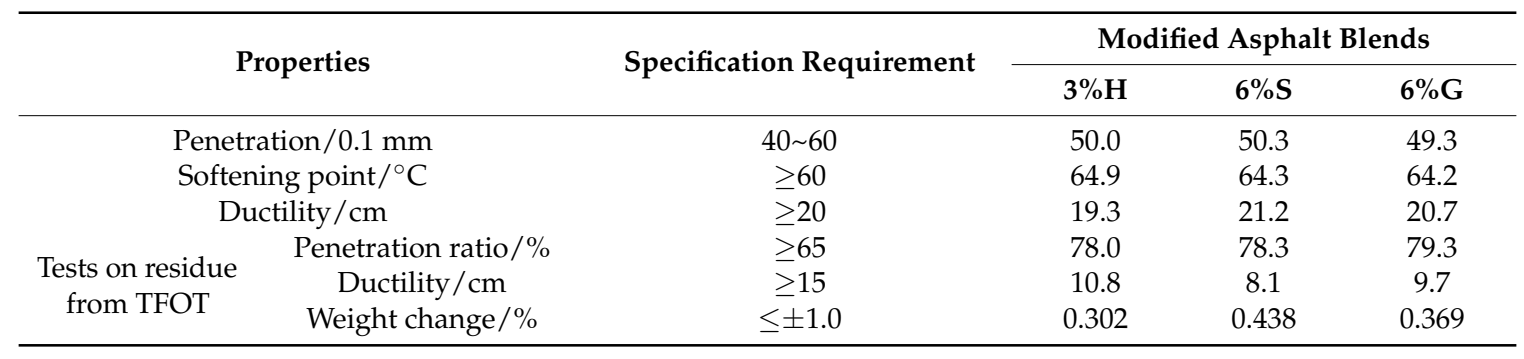


Table 7 shows that the penetration ratio and weight change of modified asphalt blends after TFOT meet the requirements of China's specifications, except in terms of ductility. The results indicate that, although the properties of aged modified asphalt blended with rejuvenating agent can be recycled, the low-temperature property often cannot meet the requirements after aging, indicating that the modifier has lost part of the original modified effect.

Therefore, modified asphalt recycling should focus on its low-temperature property, requiring rejuvenating agent not only to effectively recover the colloidal structure of aged modified asphalt, but also to repair and supplement the aged modifier. Ultimately, the objective is to recover both the low-temperature cracking resistance and high-temperature rutting resistance of modified asphalt.

\subsection{Phase Characteristics of Rejuvenating Agents on Aged Modified Asphalt}

Polymer SBS in asphalt absorbs light oil to form the polymer phase. Under the fluorescence excitation, the polymer phase reflects longer wavelength light, appearing white. In contrast, the asphalt phase does not reflect any light, appearing black. So the asphalt phase and polymer phase are clearly distinguished by fluorescence microscope. As the reflected light field is applied, there is no damage to the polymer phase distribution in the asphalt. Hence, the fluorescence microscope gets highly reproducible asphalt micrographs. By analyzing the morphological structure and dispersion state of polymer SBS in asphalt, it is possible to effectively evaluate the role of rejuvenating agent on the aged modified asphalt, and establish the relationship between macroscopic mechanical properties and microscopic characteristics of modified asphalt blends.

To ensure the reliability of fluorescence images and avoid the particularity of individual samples, three slides were made in parallel for each sample. Four representative fluorescence images were taken for each slide.

Table 8 shows the fluorescent micrographs of aged modified asphalt and modified asphalt blends with different types and proportions of rejuvenating agents.

Table 8 shows that the polymer SBS in aged modified asphalt are spherical particles distributed in the asphalt, and this modified asphalt belongs to a single-phase continuous structure, with polymer SBS as dispersed phase and asphalt phase as continuous phase. Compared with modified asphalt blended with different types and proportions of rejuvenating agents, recycling did not change its phase structure, still belonging to single-phase continuous structure. The SBS particle's uniformity is satisfactory. With the naked eye only, one cannot see the difference of SBS particle in appearance and shape. The images have to be further processed to quantify potential differences.

Professional image processing software (Image-Pro Plus) is applied to analyze and process the fluorescence images of modified asphalt blends, which can segment, count and measure the images. The area ratio of polymer SBS particles is the quantitative evaluation indexes to describe the phase characteristics and recycling mechanism of modified asphalt. Here the area ratio refers to the percentage of polymer SBS particles area to total area, indirectly reflecting the SBS swelling degree in the asphalt. 
Table 8. Fluorescence micrographs of modified asphalt.

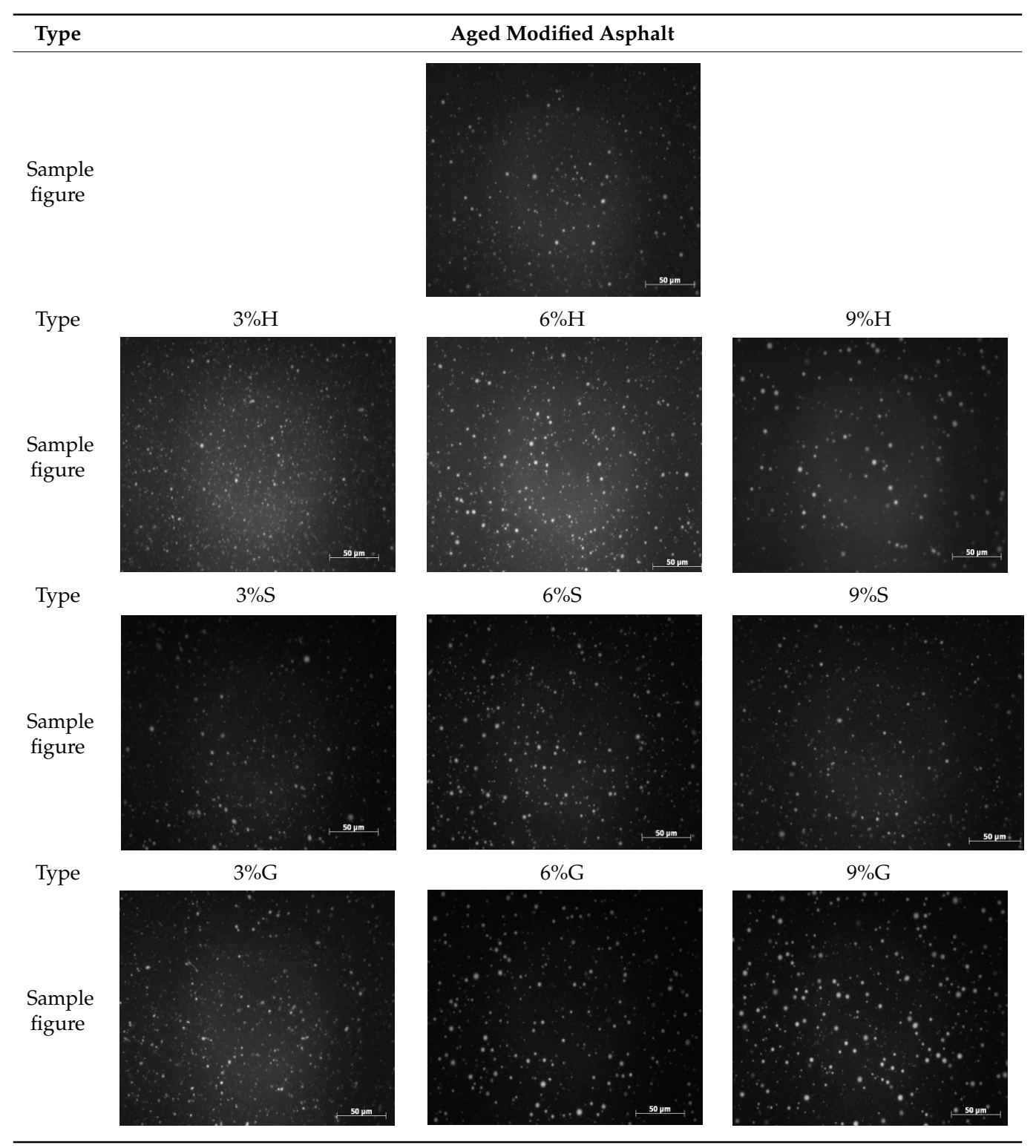

Table 9 shows the phase characteristics of modified asphalt blended with different proportions of rejuvenating agents.

Table 9. Phase characteristics of modified asphalt blends.

\begin{tabular}{ccccccccccc}
\hline \multirow{2}{*}{ Indexes } & \multirow{2}{*}{ Aged Modified Asphalt } & \multicolumn{8}{c}{ Types of Modified Asphalt Blends } \\
\cline { 3 - 9 } & & $\mathbf{3 \% H}$ & $\mathbf{6 \% H}$ & $\mathbf{9 \% H}$ & $\mathbf{3 \%}$ & $\mathbf{6 \%}$ & $\mathbf{9 \% S}$ & $\mathbf{3 \% G}$ & $\mathbf{6 \% G}$ & $\mathbf{9 \% G}$ \\
\hline Area ratio of SBS particles/\% & 2.753 & 3.679 & 2.980 & 2.030 & 3.832 & 3.672 & 3.147 & 4.207 & 4.539 & 4.081 \\
Standard deviation/\% & 0.38 & 0.51 & 0.29 & 0.31 & 0.54 & 0.57 & 0.48 & 0.46 & 0.59 & 0.32 \\
\hline
\end{tabular}

From Table 9, the area ratio of polymer SBS particles increases at first and then decreases, presumably because the proportion of rejuvenating agent was small, and the swelling effect of SBS particles continued with the action of light oil. With the increasing of the proportion of rejuvenating agent, the swelling effect reaches a certain extent, and excess of rejuvenating agent decreases the relative content of SBS particles in asphalt, resulting in the area ratio of SBS particles beginning to decrease. 
A comparison was made of the relationship of macroscopic properties shown in the Section 3.1 and the microscopic characteristics of modified bitumen blends shown in Table 9 based on the connection points of rejuvenating agent proportion. The comparison indicates that the variation of area ratio of SBS particles is consistent with the variation in tenacity.

It is concluded that with an increase of proportion of rejuvenating agent, the trend of area ratio is similar to tenacity, but this may be just an apparent phenomenon. Software statistical analysis was conducted at bivariate significance level of 0.05 . The results of modified asphalt blends are shown in Table 10.

Table 10. Correlation of area ratio of SBS particles and tenacity with proportion of rejuvenating agents.

\begin{tabular}{ccc}
\hline Rejuvenating Agent Type & Correlation Coefficient & Significance \\
\hline H & 0.953 & 0.047 \\
S & 0.983 & 0.017 \\
G & 0.957 & 0.043 \\
\hline
\end{tabular}

Table 10 shows that the correlation coefficient between area ratio of SBS particles and tenacity are all over than 0.95 , indicating that the positive correlation is strong. The significance parameters are all less than 0.05 , indicating that the two indexes have significant correlation.

According to the above research into penetration, softening point, $5{ }^{\circ} \mathrm{C}$ ductility, viscosity, and tenacity of recycled asphalt and economy, the proportion of rejuvenating agent $S$ for recycled mixtures is set to $6 \%$.

\subsection{Freeze-Thaw Split Test Results}

The moisture susceptibility of recycled mixtures is evaluated by freeze-thaw split test, and the tensile strength ratio (TSR) is used as the evaluation index. The results are shown in Table 11, and * in the study represents the addition of rejuvenating agent.

Table 11. Freeze-thaw split test results of recycled mixtures.

\begin{tabular}{cccc}
\hline RSMAP Content & No Freeze-Thaw Split Strength/MPa & Freeze-Thaw Split Strength/MPa & TSR/\% \\
\hline $0 \%$ & 0.95 & 0.87 & 91.1 \\
$30 \%$ & 1.40 & 1.12 & 80.0 \\
$30 \% *$ & 1.28 & 1.12 & 87.2 \\
$50 \%$ & 1.28 & 1.02 & 79.7 \\
$50 \% *$ & 1.31 & 1.19 & 90.8 \\
$70 \%$ & 1.33 & 0.89 & 66.9 \\
$70 \% *$ & 1.09 & 0.9 & 82.6 \\
\hline \multicolumn{4}{c}{}
\end{tabular}

Table 11 shows that TSR of recycled mixtures decreases significantly with increasing of RSMAP contents. When the RSMAP content is $70 \%$, the TSR is $66.9 \%$, which could not meet China's specification. By adding rejuvenating agent, TSR can increase significantly. This indicates that RSMAP will decrease moisture susceptibility, especially with high RSMAP contents; adding rejuvenating agent can improve the moisture susceptibility of recycled modified mixtures including high RSMAP contents. However, the moisture susceptibility of recycled mixtures is not easy to recover to HMA level.

\subsection{Semi-Circular Bending Test Results}

Figure 5 graphically illustrates the fracture energy $\left(G_{f}\right)$ and fracture toughness $\left(K_{c}\right)$ of recycled mixtures in SCB test, and RA in the Figure 5 represents rejuvenating agent. 


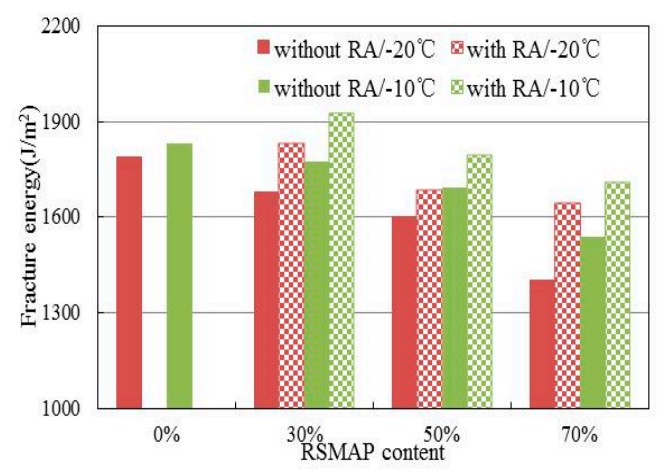

(a)

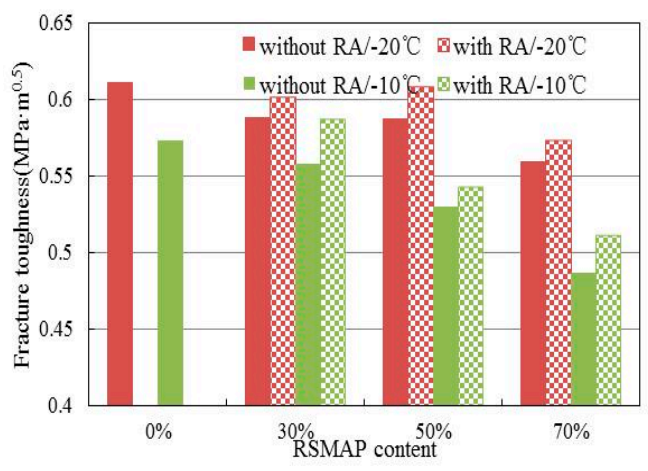

(b)

Figure 5. SCB test results of recycled mixtures. (a) Fracture energy; (b) Fracture toughness.

Figure 5 shows that the trends for SCB fracture energy and fracture toughness are decreasing with increasing RSMAP content in the mixture at the two temperatures. As the test temperature increases, the fracture energy increases and fracture toughness decreases. When the RSMAP content is 70\%, the fracture energy and fracture toughness of recycled mixture without rejuvenating agent decrease by $22 \%$ and $9 \%$ compared with the control mixtures (RSMAP is $0 \%$ ). By adding rejuvenating agent, both indexes are improved. However, the two indexes of recycled mixtures with high RSMAP contents are not easy to recover to HMA level.

This indicates that RSMAP has a negative impact on low-temperature properties of recycled mixtures, and the lower the temperature is, the greater the negative impact is. The rejuvenating agent can improve the fracture energy and fracture toughness of recycled mixtures including high RSMAP contents.

\subsection{Dynamic Modulus Test Results}

The dynamic modulus master curve model parameters (Equation (4)), developed for different recycled mixtures, are presented in Table 12.

Table 12. Dynamic modulus master curve model parameters of recycled mixtures.

\begin{tabular}{ccccccc}
\hline \multirow{2}{*}{ RSMAP Content } & \multicolumn{4}{c}{$\left|E^{*}\right|$ Master Curve Parameters } & \multicolumn{2}{c}{ Correlation Coefficient } \\
\cline { 2 - 7 } & $\delta$ & $\alpha$ & $\beta$ & $\gamma$ & $c$ & $\boldsymbol{R}^{\mathbf{2}}$ \\
\hline $0 \%$ & 2.074 & 2.311 & -0.986 & -0.689 & 8516.5 & 0.99 \\
$30 \%$ & 1.573 & 2.935 & -1.109 & -0.487 & 8356.7 & 0.99 \\
$30 \% *$ & 1.901 & 2.609 & -0.809 & -0.515 & 7249.7 & 0.99 \\
$50 \%$ & 1.116 & 3.458 & -1.360 & -0.389 & 7943.0 & 0.99 \\
$50 \% *$ & 1.717 & 2.809 & -1.094 & -0.452 & 8084.1 & 0.99 \\
$70 \%$ & 0.338 & 4.223 & -1.603 & -0.339 & 8728.1 & 0.99 \\
$70 \% *$ & 1.358 & 3.107 & -1.229 & -0.39 & 8218.9 & 0.99 \\
\hline \multicolumn{7}{c}{$*$ * the addition of rejuvenating agent. }
\end{tabular}

From Table 12 and based on the nonlinear fitting statistics, it is evident that the dynamic modulus models used for developing the master curves are highly related. The temperature shift factors for a reference temperature $20^{\circ} \mathrm{C}$ are shown in Table 13 . 
Table 13. Temperature shift factors $(\log a(T))$ of recycled mixtures.

\begin{tabular}{cccc}
\hline \multirow{2}{*}{ RSMAP Content } & \multicolumn{3}{c}{ Temperature Shift Factors $(\boldsymbol{l o g} a(\mathbf{T}))$} \\
\cline { 2 - 4 } & $\mathbf{4}{ }^{\circ} \mathbf{C}$ & $\mathbf{2 0}{ }^{\circ} \mathbf{C}$ & $\mathbf{4 0}{ }^{\circ} \mathbf{C}$ \\
\hline $0 \%$ & 1.678 & 0 & -1.857 \\
$30 \%$ & 1.647 & 0 & -1.822 \\
$30 \% *$ & 1.429 & 0 & -1.581 \\
$50 \%$ & 1.566 & 0 & -1.732 \\
$50 \% *$ & 1.594 & 0 & -1.763 \\
$70 \%$ & 1.721 & 0 & -1.903 \\
$70 \% *$ & 1.620 & 0 & -1.792 \\
\hline \multirow{4}{*}{$*$}
\end{tabular}

The dynamic modulus master curves of recycled mixtures with different RSMAP contents are provided in Figure 6. To facilitate comparison, the master curve of control mixture is also provided in Figure 6.

From Figure $6 \mathrm{a}-\mathrm{c}$, it's observed that dynamic modulus of all mixtures tested increases with the increase of the loading frequency. In general, the dynamic modulus values of recycled mixtures are significantly higher than control mixture, and the difference is greater with higher RSMAP content. By adding rejuvenating agent, the dynamic modulus decreases slightly. Figure $6 \mathrm{~d}$ shows that at higher loading frequency, there is no notable difference between the dynamic modulus of the recycled mixtures and control mixture. The results indicate that the rejuvenating agent has an effect on the stiffness of the recycled mixtures generally, but the effect is not obvious. In addition, when the loading frequency reaches a greater value, the difference of recycled mixtures and control mixture tend to be consistent, and include high RSMAP content.

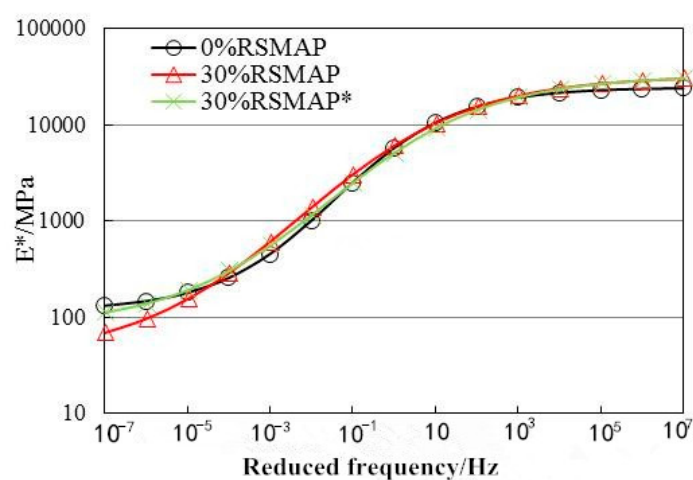

(a)

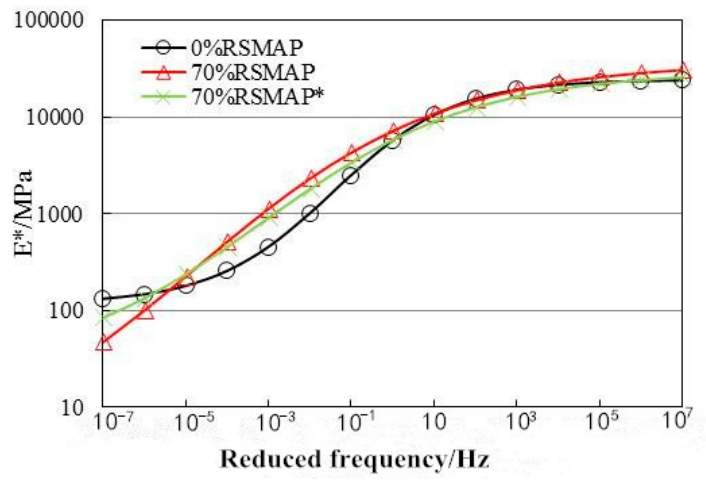

(c)

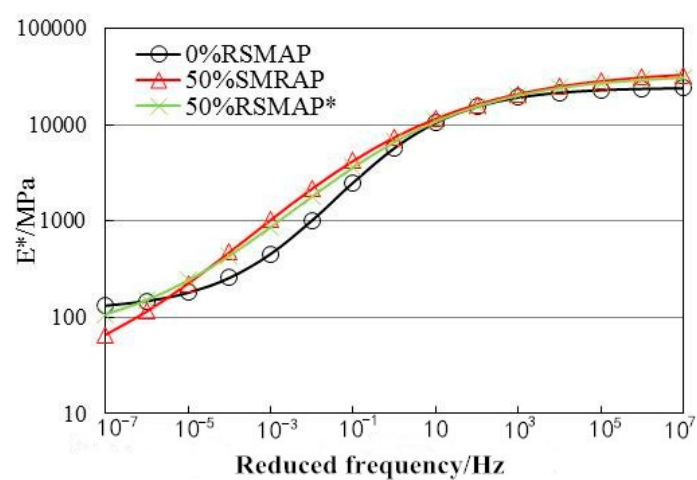

(b)

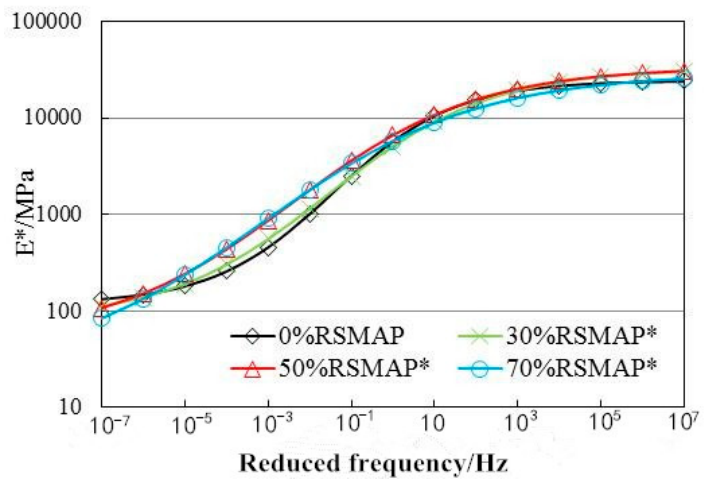

(d)

Figure 6. (a) Master curves of recycled mixtures with 30\% RSMAP; (b) Master curves of recycled mixtures with 50\% RSMAP; (c) Master curves of recycled mixtures with 70\% RSMAP; (d) Master curves of recycled mixtures with all RSMAP contents. 


\section{Conclusions}

Rejuvenating agent can effectively recycle the properties of aged modified asphalt, and improve the swelling effect between modifier and asphalt. However, the anti-aging property of modified asphalt blends is poor. The relationship between penetration and viscosity of modified asphalt blends shows that the change of penetration will be obvious when the viscosity is less than a certain value.

The recovery degree of penetration and ductility of modified asphalt blends is poorly synchronized when applying rejuvenating agent. It is not appropriate to apply the viscosity and ductility tests to carry out the recycling design at the same time.

Rejuvenating agent cannot change the phase structure of aged modified asphalt, and the SBS particle's uniformity is still satisfactory. On the basis of microscopic analysis, the SBS particles area ratio of modified asphalt blends is significantly correlated with tenacity as the proportion of rejuvenating agent increases.

RSMAP can decrease moisture susceptibility of HMA mixture, especially with high RSMAP content, and adding rejuvenating agent can improve the property. However, the property of recycled mixtures with high RSMAP content is not easy to recover to HMA mixture level.

RSMAP has a negative impact on low-temperature cracking resistance of recycled mixtures, and the lower the temperature is, the greater the negative impact is. Rejuvenating agent can improve the fracture energy and fracture toughness of recycled mixtures including high RSMAP contents. However, the recycled mixtures with high RSMAP content are not easy to recover to HMA mixture level.

In general, the rejuvenating agent has an effect on the stiffness of the recycled mixture, but not an obvious one. When the loading frequency reaches higher value, the difference of recycled mixtures and control mixture tend to be consistent, and include high RSMAP content.

Acknowledgments: This research was supported by the national Science \& Technology Support Program "The technology, equipment and demonstration for the application of reclaimed asphalt pavement (No. 2014BAC07B01)" and "Low-carbon construction technology and project demonstration of asphalt pavement (No. 2014BAC07B05)". We state that we have received funds for covering the costs to publish in open access.

Author Contributions: Jie Wang, Yongchun Qin, Songchang Huang and Jian Xu conceived and designed the experiments; Jie Wang and Wei Zeng performed the experiments; Jie Wang and Wei Zeng analyzed the data; Wei Zeng contributed materials; Jie Wang wrote the paper.

Conflicts of Interest: The authors declare no conflict of interest was reported. The founding sponsors had no role in the design of the study; in the collection, analyses, or interpretation of data; in the writing of the manuscript, and in the decision to publish the results".

\section{References}

1. Jin, H.; Gao, G.; Zhang, Y.; Zhang, Y.X.; Sun, K.; Fan, Y.Z. Improved properties of polystyrene-modified asphalt through dynamic vulcanization. Polym. Test. 2002, 21, 633-640. [CrossRef]

2. Zhang, F.; Yu, J. The research for high-performance SBR compound modified asphalt. Constr. Build. Mater. 2010, 24, 410-418. [CrossRef]

3. Khodaii, A.; Mehrara, A. Evaluation of permanent deformation of unmodified and SBS modified asphalt mixtures using dynamic creep test. Constr. Build. Mater. 2009, 23, 2586-2592. [CrossRef]

4. Khodaii, A.; Moghadas Nejad, F.; Forough, S.A.; Ahari, A.S. Investigating the effects of loading frequency and temperature on moisture sensitivity of SBS-modified asphalt mixtures. J. Mater. Civ. Eng. 2014, 26, 897-903. [CrossRef]

5. Kök, B.V.; Çolak, H. Laboratory comparison of the crumb-rubber and SBS modified bitumen and hot mix asphalt. Constr. Build. Mater. 2011, 25, 3204-3212. [CrossRef]

6. Huang, W.D.; Zheng, M.; Tang, N.P.; Shan, Z. Comparson of evaluation parameters for high temperature performance of SBS modified asphalt. J. Build. Mater. 2017, 20, 139-144.

7. Fu, H.Y.; Xie, Z.D.; Yu, M.; Dou, D.Y.; Li, L.F.; Yao, S.D. Dynamic shear rheologic properties of SBS modified asphalt. J. Highw. Transp. Res. Dev. 2005, 22, 9-12.

8. Hu, Z.W.; Sun, H.W.; Ma, S.J. Hot in-place recycling performance of SBS modified SMA mixture. J. Highw. Transp. Res. Dev. 2012, 29, 29-47. 
9. He, Z.Y.; Ran, L.F.; Cao, Q.X. Mechanism study of recycle of SBS modified asphalt based on spectrum analysis. J. Build. Mater. 2015, 18, 900-904.

10. Jamshidi, A.; Hamzah, M.O.; Shahadan, Z.; Yahaya, A.S. Evaluation of the rheological properties and activation energy of virgin and recovered asphalt binder blends. J. Mater. Civ. Eng. 2015, 27. [CrossRef]

11. Huang, S.C.; Turner, T.F. Aging Characteristics of RAP Blend Binders: Rheological Properties. J. Mater. Civ. Eng. 2014, 26, 966-973. [CrossRef]

12. Zhou, Z.G.; Yang, Y.P.; Zhang, Q.P.; Gao, J.Y. Recycling behavior of recycling agent on aged asphalt. J. Traffic Transp. Eng. 2011, 11, 10-16.

13. Cong, P.; Luo, W.; Xu, P.; Zhao, H. Investigation on recycling of SBS modified asphalt binders containing fresh asphalt and rejuvenating agents. Constr. Build. Mater. 2015, 91, 225-231. [CrossRef]

14. Sun, L.; Wang, Y.; Zhang, Y. Aging mechanism and effective recycling ratio of SBS modified asphalt. Constr. Build. Mater. 2014, 70, 26-35. [CrossRef]

15. Cong, P.; Zhang, Y.; Liu, N. Investigation of the properties of asphalt mixtures incorporating reclaimed SBS modified asphalt pavement. Constr. Build. Mater. 2016, 113, 334-340. [CrossRef]

16. Winkle, C.V.; Mokhtari, A.; Lee, H.; Williams, R.C.; Schram, S. Laboratory and field evaluation of HMA with high contents of recycled asphalt pavement. J. Mater. Civ. Eng. 2017, 29. [CrossRef]

17. Goli, A.; Ziari, H.; Amini, A. Influence of Carbon Nanotubes on Performance Properties and Storage Stability of SBS Modified Asphalt Binders. J. Mater. Civ. Eng. 2017, 29, 654-660. [CrossRef]

18. Kang, A.H.; Kou, C.J.; Liu, X.Y. Evaluation methods of dispersed phase uniformity in SBS modified asphalt based on digital image analysis technology. J. Sichuan Univ. 2014, 46, 172-176.

19. Huang, W.; Sun, L. Phase structure of modified asphalt. J. Highw. Transp. Res. Dev. 2001, 18, 1-3.

20. Sengoz, B.; Isikyakar, G. Evaluation of the properties and microstructure of SBS and EVA polymer modified bitumen. Constr. Build. Mater. 2008, 22, 1897-1905. [CrossRef]

21. Zhang, D.; Zhang, H.; Shi, C. Investigation of aging performance of SBS modified asphalt with various aging methods. Constr. Build. Mater. 2017, 145, 445-451. [CrossRef]

22. JTG E20-2011. Standard Test Methods of Bitumen and Bituminous Mixtures for Highway Engineering; China Communication Press: Beijing, China, 2011.

23. JTG E42-2005. Test Methods of Aggregate for Highway Engineering; China Communication Press: Beijing, China, 2005.

24. Zegeye, E.T.; Moon, K.H.; Turos, M.; Clyne, T.R.; Marasteanu, M.O. Low temperature fracture properties of polyphosphoric acid modified asphalt mixtures. J. Mater. Civ. Eng. 2012, 24, 1089-1096. [CrossRef]

25. Wu, Z.; Mohammad, L.N.; Wang, L.B.; Mull, M.A. Fracture resistance characterization of superpave mixtures using the semi-circular bending test. J. ASTM Int. 2006, 2, 1-15. [CrossRef]

26. Li, X.J.; Marasteanu, M.O.; Kvasnak, A.; Jason, B. Factors study in low-temperature fracture resistance of asphalt concrete. J. Mater. Civ. Eng. 2010, 22, 145-152. [CrossRef]

27. Khosravifar, S.; Haider, I.; Afsharikia, Z.; Schwartz, C.W. Application of time-temperature superposition to develop master curves of cumulative plastic strain in repeated load permanent deformation tests. Int. J. Pavement Eng. 2015, 16, 214-223. [CrossRef]

28. Ghabchi, R.; Singh, D.; Zaman, M.; Hossain, Z. Laboratory characterisation of asphalt mixes containing RAP and RAS. Int. J. Pavement Eng. 2016, 17, 829-846. [CrossRef]

29. Kupolati, W.K. Characterization of bitumen extracted from used asphalt pavement. Eur. J. Sci. Res. 2010, 7, 1663-1672. [CrossRef]

(C) 2017 by the authors. Licensee MDPI, Basel, Switzerland. This article is an open access article distributed under the terms and conditions of the Creative Commons Attribution (CC BY) license (http://creativecommons.org/licenses/by/4.0/). 